\title{
Use of information technologies for energetic portrait construction of cylindrical reinforced concrete shells
}

\author{
Oleg Kalmykov ${ }^{1}$, Ludmila Gaponova ${ }^{1}$, Petro Reznik ${ }^{1 *}$, and Sergey Grebenchuk ${ }^{1}$ \\ ${ }^{1}$ O.M.Beketov National University of Urban Economy in Kharkiv, Department of Building \\ Constructions, 61002, Kharkiv, Marshal Bazhanov str., 17 Ukraine
}

\begin{abstract}
The analysis of strain-stress state of new type of architectural and construction system 'Monofant' was examined. The analysis of the advanced graphic, computing software packages was carried out. The possibility of joint applying these packages to the problem of sustainable conjunction study of a rational combination of the geometric parameters of the design-built system "Monofant" was analyzed. From the constructive point of view, the search for the structural element shape that provides a minimum material consumption under desired conditions is of some interest. The approach based on the energy criterion of rationalization was adopted to solve this problem. Fundamentally, new opportunities in the field of building structures optimization are offered with introduction of visual programming complexes adopted for designers (Grasshopper, Dynamo). Applying the described approach to the problem of rationalizing of the constructive system "Monofant" offers the opportunity of constructing, calculating, analyzing and rationalizing of construction that has complex external and internal geometry. An illustration of a possible approach is given in a specific numerical example.
\end{abstract}

\section{Introduction}

The development of modern approaches to building construction design leads to the introduction of new systems that differ from the known solutions, generally, by more sustainable use of materials. Thus, as part of the research of the Building Structures Department of O.M.Beketov Kharkiv National University of Urban Economy under the guidance of prof. V.S. Shmukler, the design-built system "Monofant" (abbreviation "monolithic fantasy") was developed. The system was created with the comprehensive approach: technological solutions were adapted; sustainable materials and their contents were determined; and the calculation methodology was elaboarted [1]. The main idea of this system is creation of load-carrying elements made of monolithic reinforced concrete with an predefined unrestricted external shape and a complex intrinsic geometry that is provided by volume inserts storage in the reinforced concrete element body (usually from foam

\footnotetext{
*Corresponding author: engipr@gmail.com
} 
polystyrene). It has been noted that this development provides concrete savings of up to $40 \%$ and was implemented in a number of Kharkiv facilities.

a)

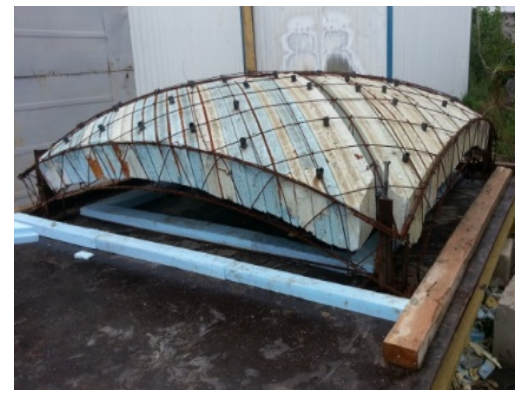

b)

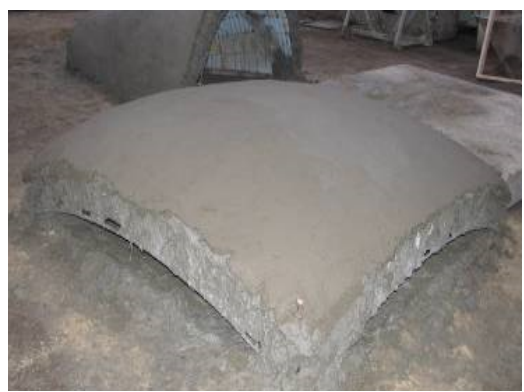

Fig.1. General view of the shell: a) prefabricated reinforcement cage with non-removable insets; b) end product.

\section{Relevance of the issue}

From the constructive point of view, the search for the structural element shape that provides a minimum material consumption under desired conditions is of some interest [2]. The approach based on the energy criterion of rationalization was adopted to solve this problem. It is considered that of all geometric parameters correlations describing the external geometry of the system, the potential energy of deformation (PED) will adopt the extreme value at their rational combination. The implementation of the approach includes determination of interrelations between the energy magnitude of the system deformation and one or more geometric parameters. Taking into account the complexity of the analyzed system configurations, forming up of such an analytical interrelation is practically impossible. This problem can be expressed numerically with the use of computing software packages. However, the operation presumes the construction of a significant number of models, that to some extent complicates the process $[3,4]$. At the same time, when it comes to constructing a finite-element model of a curvilinear shell-type system, which also has internal cavities, it is insufficient to have an interface and a graphical editor of computer complexes.

In the related research fields, for example, mechanical engineering, a similar problem occurred when the first computer complexes appeared based on the finite elements method. However, today, the analysis of the strength characteristics of parts and mechanisms is performed by importing complex geometric shapes from graphic software complexes (Inventor, SolidWorks) into calculated (Ansys, Robot) without problems [5,6]. Along with this, the rapidly growing progress in the information technologies offers fundamentally new opportunities in calculation, analysis, and, consequently, building structures optimization. The solution of a specific layer of the optimization problem is impossible without the use of specialized software, which, in its turn, is developed and upgraded taking into account the requirements and requests based on the result of development of the construction design.

Fundamentally, new opportunities in the field of building structures optimization are offered with introduction of visual programming complexes adopted for designers (Grasshopper, Dynamo). An example of this can be the article [7], where the problem of rational topology determining of the tubular bridge shell was solved using the approach of interrelation of a number of software complexes. In the work [8], the principles of the design processes optimizing, based on the interrelation of computer and graphic software packages are demonstrated using the example of trussed systems. 


\section{Objective of the study}

Applying the described approach to the problem of rationalizing of the constructive system "Monofant" offers the opportunity of constructing, calculating, analyzing and rationalizing of construction that has complex external and internal geometry. As an example, a simplified analysis of the external parameters of a cylindrical reinforced concrete shell with internal cavities will be performed (Fig.2). Two types of shells will be considered: long $(B / L=2)$ and short $(B / L=0.5)$. The variable parameter is the lifting arrow $(X[0 ; 9])$. All other parameters will be accepted as constant (Table 1).

Table 1. The adopted geometric parameters of the cylindrical shell.

\begin{tabular}{|c|c|c|c|c|}
\hline \multicolumn{2}{|c|}{ Constant parameters } & \multicolumn{3}{|c|}{ Variable parameters } \\
\hline band thickness & $50 \mathrm{~mm}$ & & $x$ & $R$ \\
\hline fin thickness & $150 \mathrm{~mm}$ & 1 & 0 & $\infty$ \\
\hline fin pitch longitudinally & $1000 \mathrm{~mm}$ & 2 & 1125 & 36562.5 \\
\hline fin pitch transversally & $1000 \mathrm{~mm}$ & 3 & 2250 & 19125 \\
\hline contour interval & $300 \mathrm{~mm}$ & 4 & 3375 & 13687.5 \\
\hline span, $L$ & $18000 \mathrm{~mm}$ & 5 & 4500 & 11250 \\
\hline width, $B$ (short shell) & $9000 \mathrm{~mm}$ & 6 & 5625 & 10012.5 \\
\hline width, $B$ (long shell) & $36000 \mathrm{~mm}$ & 7 & 6750 & 9375 \\
\hline & & 8 & 9000 & 9000 \\
\hline
\end{tabular}
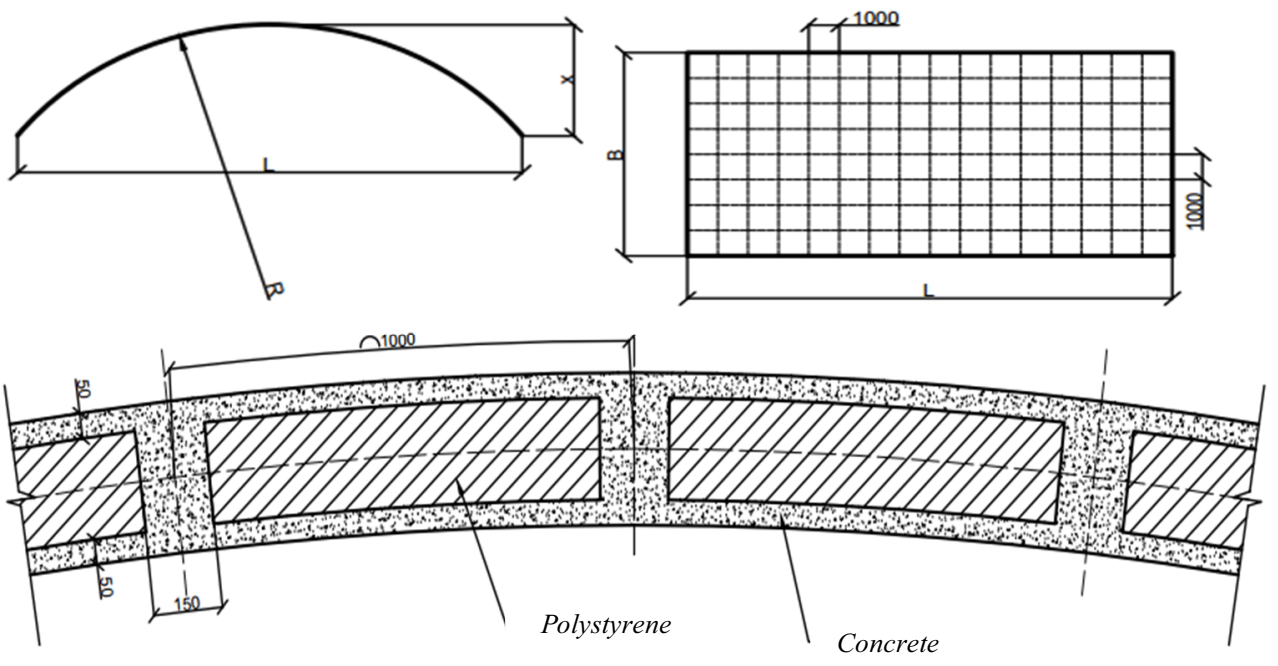

Fig. 2. Diagram of the analyzed shell.

Initially, the algorithm is written in Dynamo software package (Fig. 3). The written script allows to create automatically a 3D model of the shell by indicating its geometric parameters. Further, the script is loaded into Inventor software package (Fig. 4,a). Nastran software package is installed as an adjustment to the software package Inventor. Choosing the appropriate tab, it becomes possible to convert the created 3D model into a calculation scheme (finite element model, Fig. 4,b). Rigidity, support and load are assigned. In this case: 
a load of $200 \mathrm{~kg} / \mathrm{m}^{2}$ is applied to the upper surface, the dead load is not taken into account; the rigidity is assigned automatically by setting the class of concrete $(\mathrm{C} 25 / 30)$; the buttress is taken along the longitudinal ribs on one side hinged-fixed, on the other hand they are movable. After performing the described procedure, a calculation is performed, the result of which is the density distribution field of the electrical submersible motor, as well as the total value of the electrical submersible motor of the system (Fig.5). The described procedure is cyclic. On each subsequent cycle, the shell lifting arrow changes.

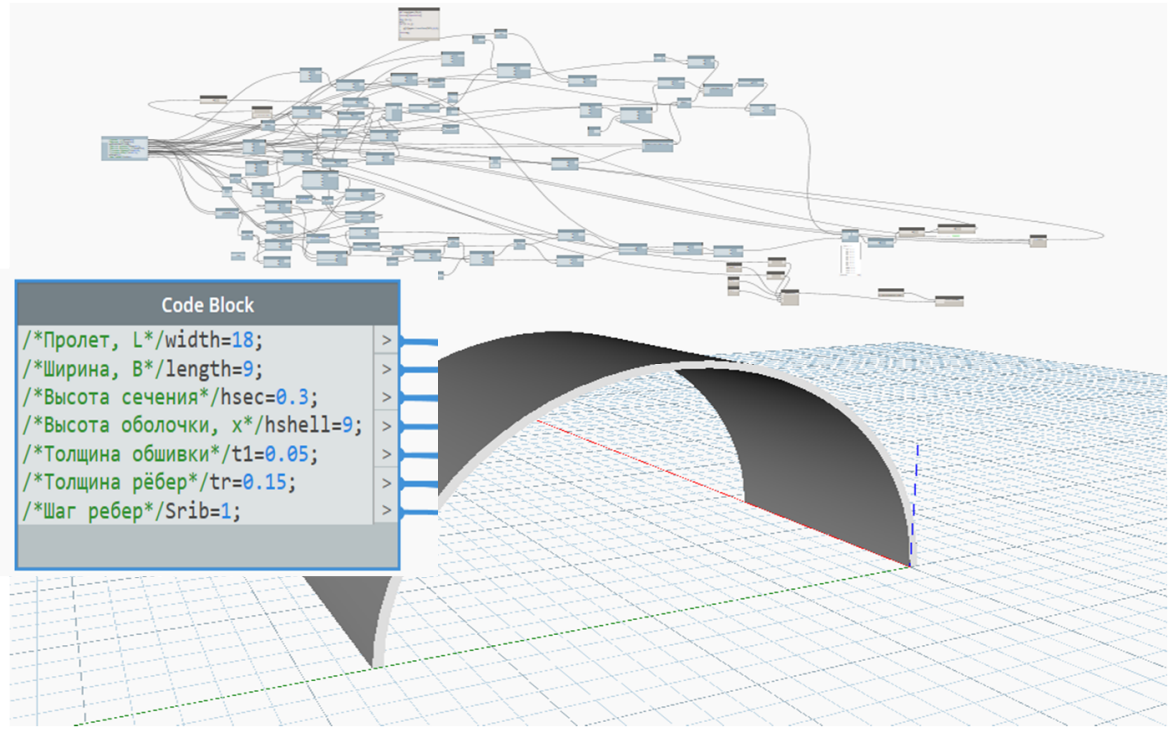

Fig. 3. Dynamo software package script for the shell topology forming.

a)

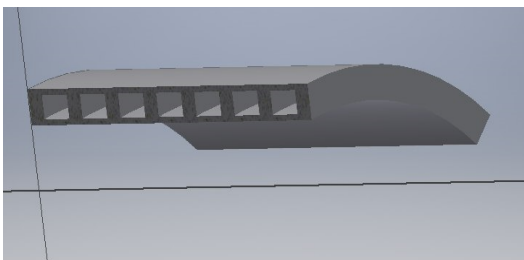

b)

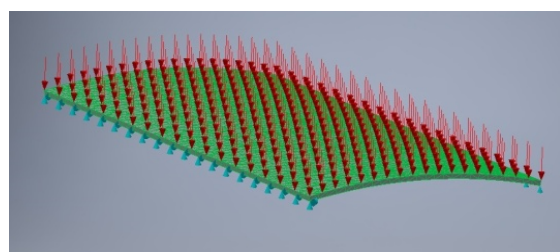

Fig. 4. General view of the shell topology in the software package: a) Inventor; b) Nastran [12].

a)

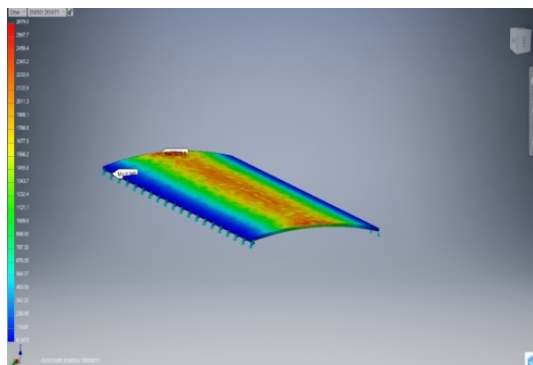

b)

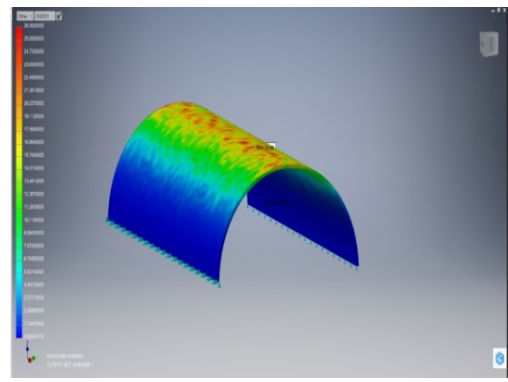

Fig. 5. Field of energy deformation distribution: a) $X=1.125 \mathrm{~m}$ b) $X=9 \mathrm{~m}$. 
As a result, the values of the electrical submersible motor for the shells were determined. Also, during the calculation, the volume of each shell was recorded (Table 2). The ratio of the structure volume to the electrical submersible motor, in this case, determines the degree of the system material tension, its dependence on the lift arrows is shown in Fig. 6.

Table 2. Results of calculation.

\begin{tabular}{|c|c|c|c|c|c|c|}
\hline$X, \mathrm{~m}$ & \multicolumn{3}{|c|}{$B / L=0.5$} & \multicolumn{3}{c|}{$B / L=2$} \\
\cline { 2 - 7 } & $\begin{array}{c}\text { Energy } U, \\
\text { relative } \\
\text { unit }\end{array}$ & $\begin{array}{c}\text { Volume } \\
V, \mathrm{~m}^{3}\end{array}$ & $U / V$ & $\begin{array}{c}\text { Energy } U, \\
\text { relative } \\
\text { unit. }\end{array}$ & $\begin{array}{c}\text { Volume } \\
V, \mathrm{~m}^{3}\end{array}$ & $U / V$ \\
\hline 0 & 1.171204 & 25.7 & 4.557214 & 4.569075 & 101.5 & 4.501552 \\
\hline 1.125 & 1.17504 & 25.9 & 4.536834 & 4.58597 & 102.3 & 4.482864 \\
\hline 2.25 & 1.212534 & 26.9 & 4.507561 & 4.745556 & 106.3 & 4.464305 \\
\hline 3.375 & 1.281871 & 28.1 & 4.561819 & 5.027976 & 110.8 & 4.537884 \\
\hline 4.5 & 1.373526 & 29.9 & 4.593732 & 5.406874 & 118.1 & 4.578217 \\
\hline 5.625 & 1.4562 & 31.8 & 4.579245 & 5.729 & 125.4 & 4.568581 \\
\hline 6.75 & 1.54325 & 34.3 & 4.499271 & 6.0452 & 135.5 & 4.461402 \\
\hline 9 & 1.631011 & 40.2 & 4.057241 & 6.416271 & 158.7 & 4.043019 \\
\hline
\end{tabular}

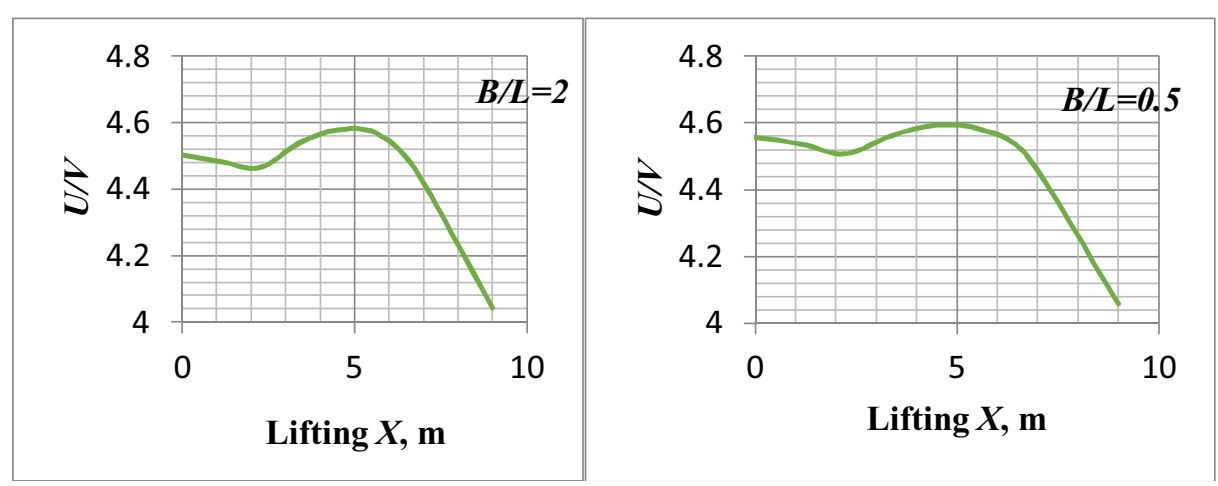

Fig.6. Dependence of the shell lifting arrow on the ratio of the system deformation energy to the volume.

From these diagrams it follows that for the considered standard sizes of cylindrical reinforced concrete shells, the function acquires an extreme value of the corresponding lifting arrow $X \approx 5 \mathrm{~m}$. In this formulation of the problem, denoted value is considered as sustainable.

\section{Conclusion}

Application of the corresponding approach to the problem of finding sustainable shapes of the construction system "Monofant" offers significant opportunities in this field. It is noted that the described formulation shows the possibility of solving similar problems, once the external parameter is considered. The search for sustainable combinations of internal parameters of similar systems is of certain interest in further research.

\section{References}

1. V. Shmukler, V. Babayev, Bugayevskiy S., Berezhna K., Kariakin I., Kondrashchenko V., Seirski I. Framework Building “MONOFANT” 89464 Ukraine 
2. Shmukler V., Klymov Y., Burak M. Frameworks of Hollow Core Types. (Kharkiv: Golden Pages, 2008)

3. Li Xue-ping, Zhao Lian-yu, Liu Zheng-zhong, MATEC Web of Conferences 95 (2017)

4. E. Carrera. Arch. Comput. Meth. Engng,. 9(2) 87-140, (2002)

5. M. Yaghoubi, S.S. Mohtasebi, A. Jafari, H. Khaleghi. Design and manufacture of a new and simple mechanism for transmission of power between crossover shafts up to 135 degrees for farm. (XVIIth World Congress of the International Commission of Agricultural and Biosystems Engineering Hosted by the Canadian Society for Bioengineering Québec City, Canada, 2010)

6. Bankole I. Oladapo, Balogun A. Vincent, Augustine O. Oke, Esoso A. Agbor. Design And Finite Element Analysis On Car Seat Height Screw Adjuster Using Autodesk Inventor (Dept. Of Mechanical \& Mechatronics Eng,Afe Babalola University, Ado-Ekiti, Nigeria Volume 2 Issue 8, August 2015)

7. Mathis Chlosta Master's thesis. "Feasibility study on fiber reinforced polymer cylindrical truss bridges for heave trafic" Netherlands (2012)

8. Mehdi Nourbakhsh Generalizable surrogate models for the improved early stage exploration of structural design alternatives in building construction. (School of Building Construction Georgia Institute of Technology 2016). 